\title{
Serotonin 5-HT1A Receptors Modulate Hippocampal Reactivity to Afferent Stimulation
}

\author{
Y. Levkovitz and M. Segal \\ Department of Neurobiology, The Weizmann Institute, Rehovot 76100, Israel
}

\begin{abstract}
Hippocampal dentate gyrus reactivity to perforant path (PP) stimulation in the anesthetized rat was enhanced after systemic administration of the serotonin-releasing drug fenfluramine (FFA). This effect of FFA was mimicked by local application of the drug via the recording pipette, indicating that the effect of FFA is mediated by release of serotonin from intrahippocampal serotonergic terminals. The 5-HT1a antagonist NAN-190 and the 5-HT1b agonist CGS-12066-B, applied both systemically and locally, blocked the effect of FFA. This blocking action was not shared by the $5-\mathrm{HT} 2-4$ receptor agonists or antagonists tested. The 5-HT1a receptor agonist 8-OH-DPAT, applied systemically, caused a marked reduction in population spike responses to PP stimulation, whereas an opposite effect was
\end{abstract}

produced by local application of this drug. The effect of peripheral application of 8-OH-DPAT was blocked by depletion of serotonin. The local effect of FFA was blocked by a reducing neurotransmitter release with a pipette containing $10 \mathrm{~mm} \mathrm{Mg}^{2+}$. Finally, local application of the GABA antagonist picrotoxin also enhanced population spike response to PP stimulation, and the effects of picrotoxin and FFA occluded. These results indicate that serotonin released from terminals in the hippocampus activates a 5-HT1a receptor on interneurons that suppresses their activity and thus enhances dentate granular cell population spike response to PP stimulation.

Key words: hippocampus; serotonin; fenfluramine; interneurons; 5-HT1a receptor; GABA
The hippocampus is a major target of serotonergic afferents arising from the midbrain raphe nuclei. Serotonin [5-hydroxytryptamine (5-HT)]-containing fibers enter the dorsal hippocampus via the fornix and the supracallosal bundles and innervate the dentate hilus extensively and the other parts of the hippocampus (Azmitia and Segal, 1978) more diffusely. Specifically, serotonin-containing fibers terminate on inhibitory interneurons of the hippocampus (Freund et al., 1990). The effects of 5-HT are mediated by its binding to a family of at least nine postsynaptic 5-HT receptor subtypes (Biegon et al., 1982; Hoyer, 1988; Julius et al., 1990; Jacobs and Azmitia, 1992; Peroutka, 1993). Several actions of serotonin on electrophysiological properties of neurons in the hippocampus have been described, including a 5-HT1a receptor-mediated activation of a potassium current, which hyperpolarizes interneurons preferentially, (Segal, 1990) and a 5-HT3 receptor-mediated depolarization of interneurons (Ropert and Guy, 1991). On a network level, 5-HTreleasing drugs [D-fenfluramine (FFA) and $p$-chloramphetamine (PCA)] facilitate reactivity of the dentate gyrus (DG) to stimulation of the excitatory perforant path (PP) arising in the entorhinal cortex (Richter-Levin and Segal, 1990). The 5-HT releasers cause an increase in population spike with no concomitant change in the EPSPs, indicating that the effect is not exerted at the PP synapse, but between the synapse and the spike-generating mechanism in the granular layer (Richter-Levin and Segal, 1990). The objective of the present study is to identify the serotonin receptor subtype mediating this facilitatory action of FFA in the DG, with the two main candidates being a 5-HT1a receptor, which acts to inhibit interneurons, or a 5-HT3 receptor, which

Received March 19, 1997; revised April 22, 1997; accepted April 28, 1997.

We thank Ms. V. Greenberger for help with immunohistochemistry.

Correspondence should be addressed Dr. Menahem Segal, Department of Neurobiology, The Weizmann Institute, Rehovot 76100, Israel.

Copyright (C) 1997 Society for Neuroscience $0270-6474 / 97 / 175591-08 \$ 05.00 / 0$ excites interneurons. To this end, we used both parenteral and local administration of serotonin releasers and receptor ligands and propose that this effect is mediated primarily by activation of a 5-HT1a receptor at inhibitory interneurons in the dentate hilus.

\section{MATERIALS AND METHODS}

Adult, male hooded rats (250-350 gm) were housed in a temperaturecontrolled room, three per cage with a 12:12 hr light/dark cycle and access to food and water ad libitum.

Rats were anesthetized with urethane ( $21 \%$ solution, $1.2 \mathrm{~g} / \mathrm{kg}$, i.p.) and placed in a stereotaxic apparatus where they were prepared for recording. A bipolar $125 \mu \mathrm{m}$ stimulating electrode was implanted in the PP (coordinates: $7.5 \mathrm{~mm}$ posterior to bregma; $3.0 \mathrm{~mm}$ lateral to the midline; depth, $3.5 \mathrm{~mm}$ ). Recording micropipettes with a tip diameter of 2-3 $\mu \mathrm{m}$ were filled either with $2 \mathrm{M} \mathrm{NaCl}$ or with the tested drug solution, prepared in $\mathrm{NaCl}$, and moved into the DG with an hydraulic microdrive (coordinates: $4 \mathrm{~mm}$ posterior to bregma; $3.0 \mathrm{~mm}$ lateral; depth adjusted to yield the largest EPSP response to PP stimulation applied with a pulse duration of $100 \mu \mathrm{sec}$. When a drug-containing pipette was used, it was introduced into the same location as the previous, control pipette. This was verified by the production of the same EPSP to the same stimulation intensity right after driving the pipette into the same location below the reversal point of the EPSP in the granular cell layer. Using this protocol, drug-containing and control pipettes could be alternated several times in the same experiment. The spread of chemicals from the tip of the pipette was assessed in sample cases, using 5-HT immunohistochemistry after the use of pipettes containing 5-hydroxytryptophane. The rat was perfused transcardially with $4 \%$ paraformaldehyde after the placement of the micropipette into the DG for $20 \mathrm{~min}$. Subsequently, the brain was sectioned and stained as detailed elsewhere (Levkovitz et al., 1996). Enhanced staining for 5-HT was seen in the area of the pipette, extending no farther than $0.5 \mathrm{~mm}$ around the tip. Evoked responses were amplified and filtered at $1 \mathrm{~Hz}$ to $1 \mathrm{kHz}$. Off-line measurements of the slopes of the EPSPs (in volts/sec) and magnitudes of the maximal population spike (in millivolts) were made using averages of 10 successive responses to a given stimulation intensity applied at a rate of $0.1 \mathrm{~Hz}$. Population spike size and EPSP slope were measured as described previously (Richter-Levin and Segal, 1990). At stimulation intensities that yielded $50 \%$ of the maximal responses, the EPSP slope at baseline condition was $7.32 \pm 0.95 \mathrm{mV} / \mathrm{msec}$, and the population spike was $2.17 \pm$ 

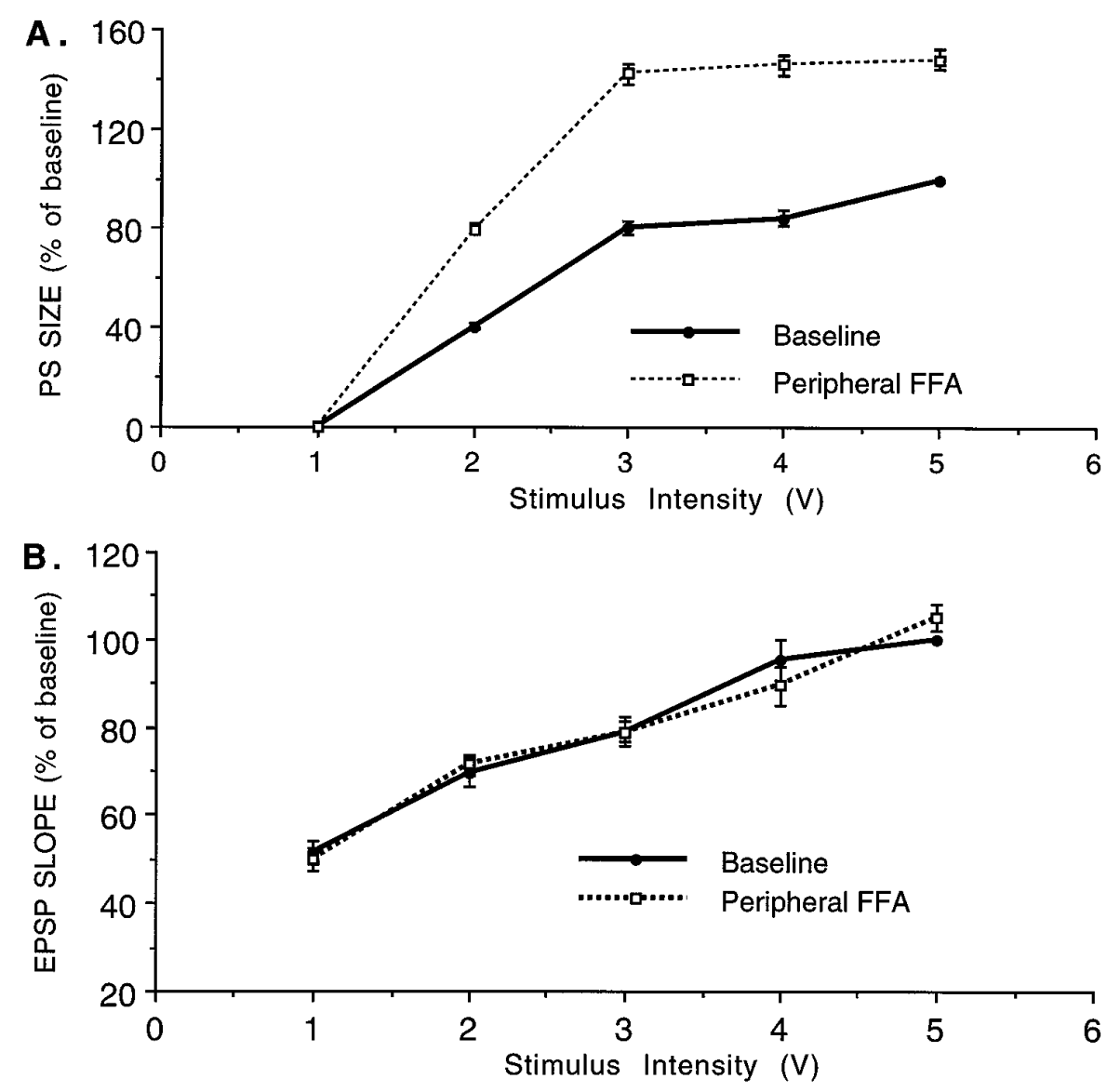

Figure 1. Peripheral application of FFA produces a large and sustained increase in population spike response of dentate granular cells to PP stimulation. $A$, Input-output relationships of the population spikes to increasing magnitudes of stimulation of the PP before and $\sim 20$ min after intraperitoneal injection of $7.5 \mathrm{mg} / \mathrm{kg}$ FFA. $B$, Same, measuring the EPSP slopes after drug application relative to controls. $C$, Stability of the population spike responses measured over $1 \mathrm{hr}$ after application of the drug. In all cases, $100 \%$ is the maximal response measured in the control condition. In $C$, the stimulation, which was chosen for continuous monitoring, produced $80 \%$ of the maximal control response in the control condition. In subsequent drug experiments, the stimulation that produced $80 \%$ of maximal control values was chosen for monitoring of drug effects.

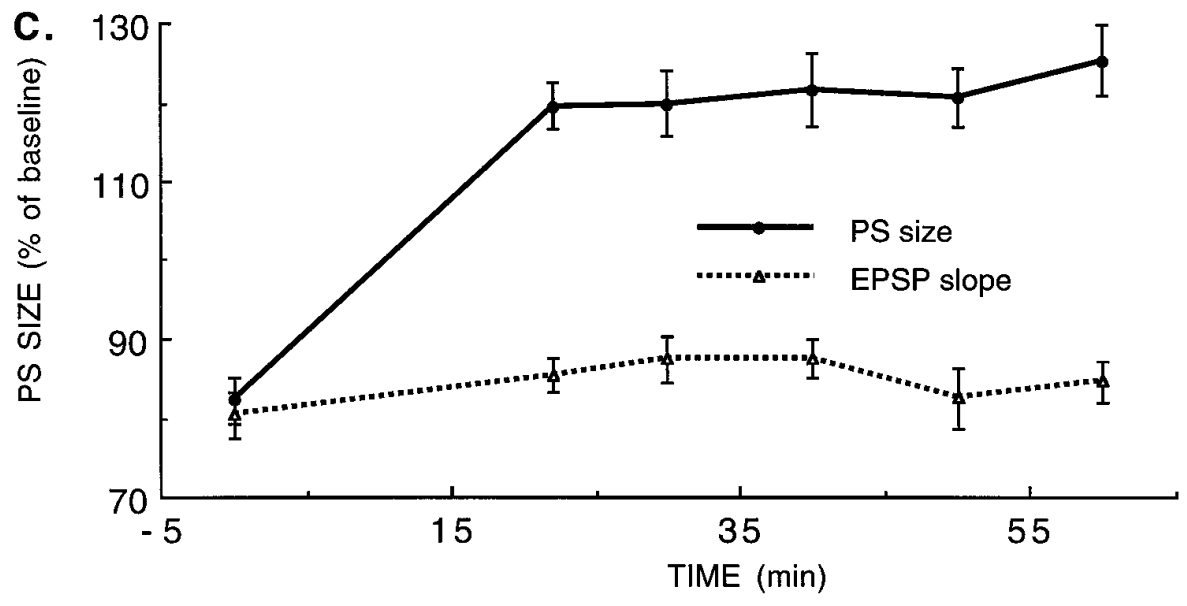

$0.61 \mathrm{mV}$. To standardize the calculations of the drugs effects, the magnitudes of all responses were related to the predrug response to maximal stimulation intensity used $(100 \%)$. Paired $t$ tests were used for statistical analysis unless otherwise indicated. Results are presented as mean \pm SEM.

\section{RESULTS}

\section{Effects of peripheral and local application of FAA}

Intraperitoneal injection of FFA $(7.5 \mathrm{mg} / \mathrm{kg}$, i.p.) caused a consistent and significant $55 \%$ increase in population spike produced by dentate granule cells in response to PP stimulation $(n=7$ rats, $p<0.0001$ ) (Fig. 1). The main effect of FFA was on the size of the population spike (Fig. $1 A$ ), and there was no systematic effect on the slope of the rising phase of the EPSP, as seen before (RichterLevin and Segal, 1990) (Fig. 1B). The effect of FFA was seen within 5 min of the drug application and was persistent for at least 30 min of recording without a significant reduction (Fig. 1C). This increase in the ratio of population spike to EPSP slope suggests a change in the excitability of granular cells rather than a change in transmission at the PP synapse.

FFA can cause release of serotonin from terminals throughout the brain, including those residing on somata of serotonergic neurons in the brainstem and those residing on afferent regions to the hippocampus, i.e., the septal nuclei and entorhinal cortex. Although previous experiments indicated that a remote site (e.g., serotonin-containing terminals in the septum) is less likely to cause the change in hippocampal excitability than a local site within the hippocampus (Richter-Levin and Segal, 1990), a rigorous test of this option should involve direct application of FFA 

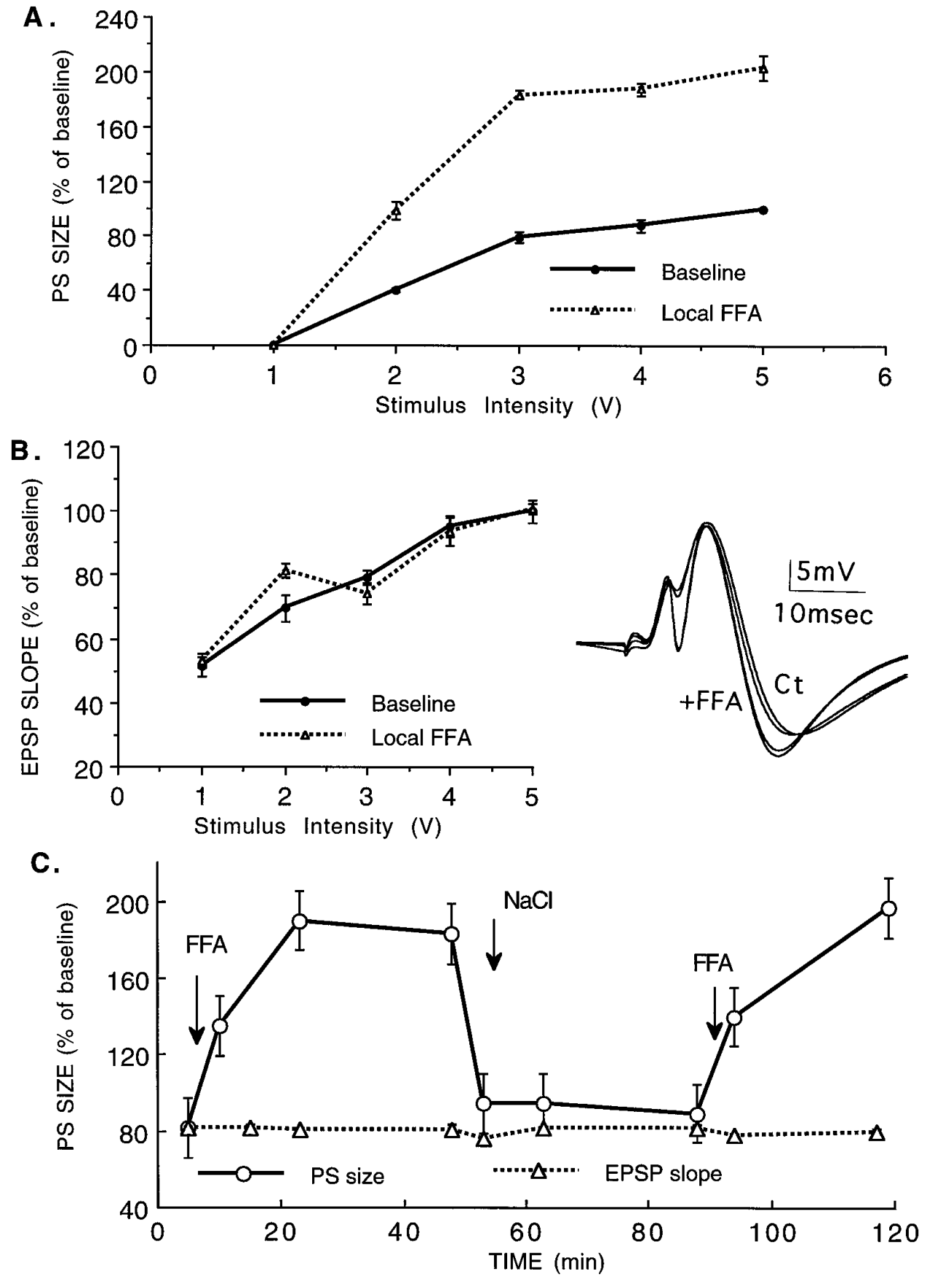

Figure 2. Local application of FFA causes an increase in population spike response to PP stimulation. FFA leaked through the recording pipette while measuring electrophysiological response to PP stimulation. $A$, A marked increase in population spike is seen with all stimulation intensities, by comparison to a control pipette, used at the same recording location. $B$, This is not accompanied by a change in population EPSPs. Inset illustrates sample responses recorded with $\mathrm{NaCl}$ - and FFA-containing pipettes alternately at the same site. Note the large increase in population spike in the presence of FFA. $C$, Insertion of a recording pipette at the site that was recorded previously with an $\mathrm{NaCl}$-containing pipette shows a larger population spike with the same EPSP (as in inset in B). Replacement of the recording drugcontaining pipette with an $\mathrm{NaCl}$ containing pipette restored the original population spike. This procedure can be repeated several times with considerable stability. in the DG. FFA, applied in the recording pipette (at a concentration of $10 \mathrm{~mm}$ but not at concentrations of 0.1 or $1 \mathrm{~mm}$ ) caused, in fact, a large increase in population spike. We found an increase of $60-90 \%$ in population spike response of granule cells to PP stimulation $(n=5, p<0.0006)$ (Fig. $2 A)$. At all stimulation intensities used, there was no effect of FFA on the slope of the EPSPs. (Fig. 2B).

The increase in population spike was seen within 3 min after placement of the drug-containing pipette into the $\mathrm{DG}$ and reached a maximum 7-8 min later. No additional change was noticed up to $55 \mathrm{~min}$ after placement of the drug-containing pipette (Fig. 2C). However, replacement of the drug-containing pipette with a control pipette containing $\mathrm{NaCl}$ caused a rapid restoration of the population spike to its original level (Fig. 2C), indicating that the change in population spike was dependent on continuous presence of FFA in the hippocampus and that no long-term change in reactivity of the hippocampus to afferent stimulation was produced by the drug. These experiments indicate that FFA acts locally to release serotonin from its terminals in the DG and cause a large increase in reactivity to afferent stimulation.

\section{Serotonergic receptors involved in FFA action in the hippocampus: 8-OH-DPAT}

To study the serotonin receptor subtype activated by the released serotonin, we injected different serotonin receptor agonists and antagonists systemically and examined their effects both on baseline responses to PP stimulation (Table 1) and on hippocampal 


\begin{tabular}{|c|c|c|c|c|}
\hline Function & Drug & Dosage & $\begin{array}{l}\text { Change } \\
(\%)\end{array}$ & $\begin{array}{l}\text { Rats } \\
(n)\end{array}$ \\
\hline \multirow[t]{2}{*}{ Agonist 1a } & 8-OH-DPAT & $0.2 \mathrm{mg} / \mathrm{kg}$ & $-47 \pm 3.6$ & 9 \\
\hline & PCPA/DPAT & $0.2 \mathrm{mg} / \mathrm{kg}$ & $59 \pm 1.5$ & 6 \\
\hline Antagonist 1a & NAN-190 & $3 \mathrm{mg} / \mathrm{kg}$ & $5 \pm 2.0$ & 6 \\
\hline Agonist 1b & CGS-12066-B & $0.75 \mathrm{mg} / \mathrm{kg}$ & $-1 \pm 1.4$ & 5 \\
\hline Antagonist 2 & Mianserin & $5 \mathrm{mg} / \mathrm{kg}$ & $3 \pm 1.6$ & 5 \\
\hline \multirow[t]{7}{*}{ Antagonist 3} & Ondansetron & $50 \mu \mathrm{g} / \mathrm{kg}$ & $0 \pm 1.6$ & 5 \\
\hline & Ondansetron & $0.2 \mathrm{mg} / \mathrm{kg}$ & $2.3 \pm 1.2$ & 8 \\
\hline & Ondansetron & $0.6 \mathrm{mg} / \mathrm{kg}$ & $2 \pm 1.8$ & 7 \\
\hline & DAU 6215 & $0.2 \mathrm{mg} / \mathrm{kg}$ & $2.4 \pm 2.0$ & 6 \\
\hline & DAU 6215 & $0.6 \mathrm{mg} / \mathrm{kg}$ & $-7 \pm 2.7$ & 6 \\
\hline & DAU 6285 & $0.2 \mathrm{mg} / \mathrm{kg}$ & $3.3 \pm 1.7$ & 5 \\
\hline & DAU 6285 & $0.6 \mathrm{mg} / \mathrm{kg}$ & $3 \pm 1.7$ & 6 \\
\hline Agonist 4 & BIMU 1 & $0.6 \mathrm{mg} / \mathrm{kg}$ & $-1 \pm 1.6$ & 4 \\
\hline
\end{tabular}

reactivity to FFA. For each drug tested, the changes in reactivity of the DG to PP stimulation were examined by constructing input-output curves before and after drug application. Several drugs were tested with a range of the effective concentrations reported to block the selective serotonin receptor.

The 5-HT1a receptor agonist 8-OH-DPAT, injected intraperitoneally $(0.2 \mathrm{mg} / \mathrm{kg})$, caused a significant $(47 \pm 3.6 \%)$ decrease in the population spike, with no effect on the slope of EPSP $(n=9$, $p<0.005$ ) (Fig. 3). The effect was seen within 5-10 min after drug application. As with FFA, this strong depressant action of 8-OHDPAT can be exerted either at the local site within the hippocampus or at a remote site, for example, at the serotonin 5-HT1a autoreceptor in the raphe nuclei (Hall et al., 1985). Therefore, we examined the effect of local application of 8-OH-DPAT via the recording pipette on population responses to PP stimulation. Local application of 8-OH-DPAT at a pipette concentration of 10 $\mathrm{mM}$ (attempted on three rats, with a pipette concentration of 1 $\mathrm{mM}$, with no effect) caused a marked increase in population spike over baseline, as seen with FFA $(n=5, p<0.001)$ (Fig. 3). Peripheral injection of 8-OH-DPAT before its local application did not block the marked enhancing action of the locally applied drug $(n=7, p<0.001)$.

The distinction between the peripheral and local sites of actions of 8-OH-DPAT became more apparent when serotonin synthesis was blocked by $p$-chlorophenyl alanine (PCPA) (Koe and Weissman, 1986). In previous studies (Richter-Levin and Segal, 1990), PCPA blocked the action of peripheral administration of FFA. In the present studies, injection of PCPA (400 $\mathrm{mg} / \mathrm{kg}$ ) $3 \mathrm{~d}$ before the recording experiment not only reversed the suppressing action of peripheral 8-OH-DPAT, but now the drug caused a large increase in population spike with no effect on the slope of the EPSPs, as is the effect of 8-OH-DPAT applied locally ( $n=6, p<0.05$ ) (Fig. 3), suggesting that in the absence of serotonin synthesis and release, the postsynaptic, intrahippocampal action of 8-OH-DPAT dominates.

\section{5-HT receptors mediating the effect of FFA: peripheral drug applications}

The marked local effect of 8-OH-DPAT indicates that a 5-HT1a receptor is involved in the action of FFA. With the exception of 8-OH-DPAT, none of the agonists and antagonists tested affected baseline reactivity to PP stimulation (Table 1$)$. Tested against the effects of FFA, the 5-HT1a antagonist NAN-190 $(3 \mathrm{mg} / \mathrm{kg})(n=$
$6, p<0.005$ ) was the only one to completely block the effects of FFA. None of the other antagonists used affected the response to FFA. A high dose of 5HT-3 antagonist ondansetron $(600 \mu \mathrm{g} / \mathrm{kg})$ $(n=6, p<0.005)$ reduced partially but significantly the effect of FFA (Fig. 4). Interestingly, the 5-HT-1b agonist CGS-12066-B, at a fairly low concentration $(0.75 \mathrm{mg} / \mathrm{kg} ; n=5, p<0.0001)$, also blocked the effects of FFA.

\section{5-HT receptors mediating the effect of FFA: local drug applications}

Several of the drugs used for peripheral application were also applied via the recording pipette, at a drug concentration of 10 mM. In none of the cases studied (NAN-190, $n=5$; CGS-12066-B, $n=5$; Mianserin, $n=5$; Ondansetron, $n=5$; DAU-6215, $n=5$; DAU-6285, $n=5$ ) did the drug affect reactivity of the DG to afferent stimulation, as compared with recording with an $\mathrm{NaCl}$ containing pipette, before and after use of the drug-containing pipette. When tested after peripheral FFA application (Fig. 5), NAN-190 was the only drug to reduce substantially the FFAinduced elevation of the population spike response $(p<0.01)$. Among the other drugs tested, the 5-HT1b agonist had a partial but significant blocking action $(p<0.05)$, whereas the other drugs were ineffective. These experiments indicate that the lack of effect of the various drugs tested is not attributable to their lack of penetration into the brain and that the 5-HT1a receptor antagonist is blocking the effect of FFA in the hippocampus. Taken together with the results of the effect of 8-OH-DPAT, the present results strongly suggest that release of serotonin in the hippocampus activates $5 \mathrm{HT} 1 \mathrm{a}$ receptors to enhance reactivity of the hippocampus to afferent stimulation.

\section{Serotonin interacts with GABA interneurons to increase reactivity to stimulation}

The only known effect of serotonin, acting at a 5-HT1a receptor, is to activate $\mathrm{K}$ current, which hyperpolarizes cells and suppresses its activity (Segal, 1980). How then can activation of 5-HT1a receptors cause an enhancement of reactivity to afferent stimulation? One possibility is that feedforward inhibitory interneurons are those affected by the released serotonin, and when they are inhibited, a facilitation of reactivity of the granular neurons ensues. To test this possibility, we applied a GABA antagonist, bicuculline, through the recording electrode and measured the changes in population spike response to PP stimulation. In four animals tested, application of peripheral FFA was followed by replacement of the recording $\mathrm{NaCl}$ electrode with one containing $1 \mathrm{~mm}$ bicuculline. FFA caused the typical $60 \%$ increase in population spikes, and bicuculline produced an additional increase in this response by more than twofold (Fig. 6A). This was not accompanied by a change in population EPSP slopes. If, however, recording was first made in control conditions followed by recording with a bicuculline-containing pipette, bicuculline caused a marked (more than twofold) increase in population spike (Fig. $6 B)(n=5)$, but FFA was no longer able to produce an additional increase in this response. The occlusion of FFA and bicuculline effects was not attributable to saturation of the ability to produce a population spike by bicuculline, because the input-output relationships at low stimulation intensity also expressed an occluded response (Fig. 6B)

\section{The effect of FFA is blocked by $\mathbf{M g}^{\mathbf{2 +}}$}

If indeed FFA acts by releasing serotonin, which hyperpolarizes interneurons and prevents their inhibition of granular cells, then modulating transmitter release should also affect the ability of 


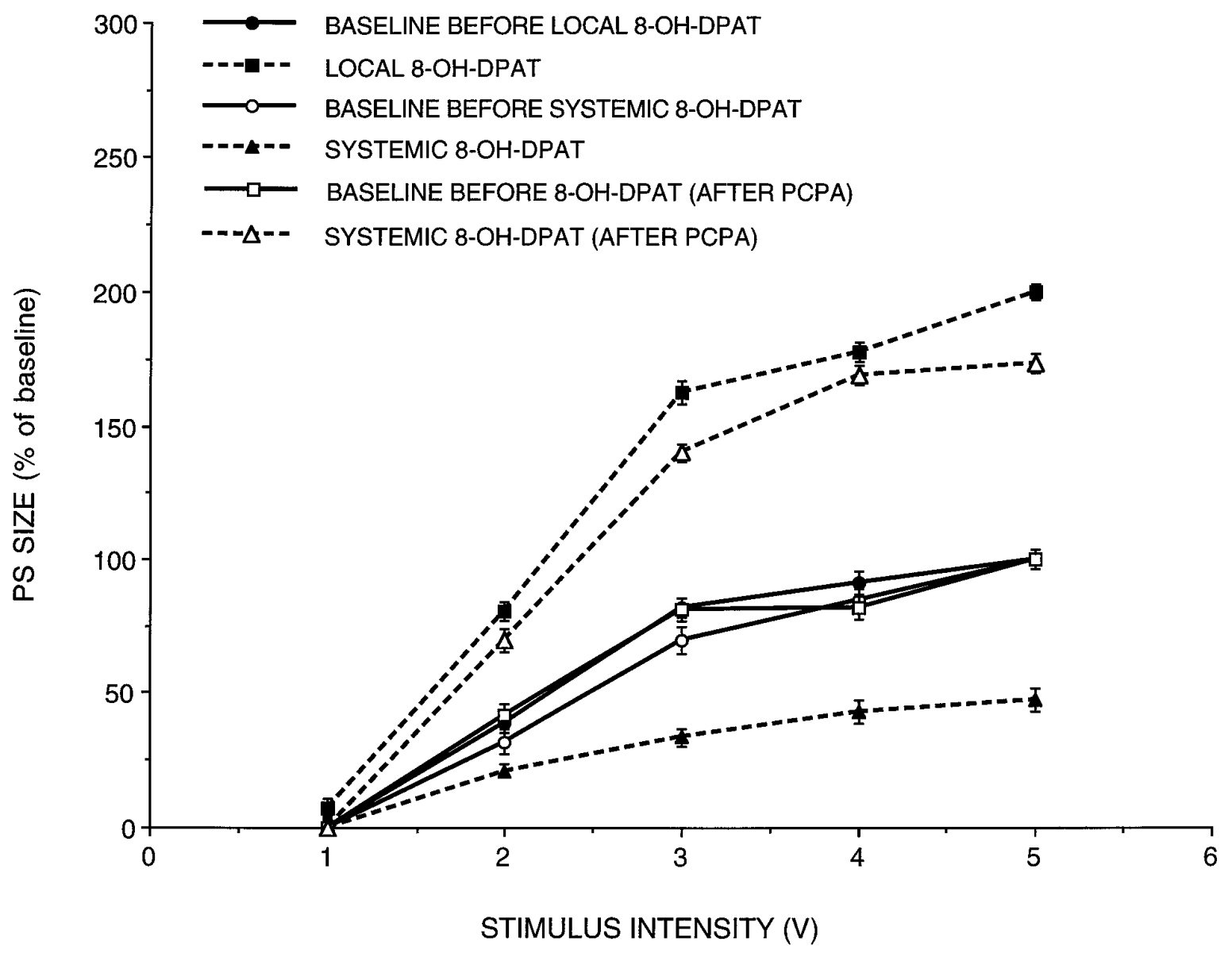

Figure 3. The effect of FFA is mimicked by local application of the 5-HT1a agonist 8-OHDPAT, but not by its systemic application. Input-output relationships are depicted in control, after systemic application of the drug, after its local application, and after its systemic application in animals depleted of serotonin by treatment with PCPA. A marked suppression of population spike is seen with peripheral application of the drug, which is reversed into enhancement in PCPA-treated rats.

FFA to exert its action. The effect of $10 \mathrm{mM} \mathrm{Mg}^{2+}$ in the recording pipette on population spike and its enhancement by FFA were measured in three rats (Fig. 7). In preliminary experiments, $20-50 \mathrm{mM} \mathrm{Mg}^{2+}$ in the pipette caused a marked reduction of EPSP slope, probably because it reduced release of neurotransmitter in the PP (data not shown). On the other hand, a pipette containing $10 \mathrm{mM} \mathrm{Mg}^{2+}$, placed in or below the granular layer, did not affect the slope of the EPSP, but enhanced population spike by $\sim 60 \%$ over control values. FFA, in the same rats, produced a large increase in population spike (Fig. $7 A$ ), but when tested in a pipette that also contained $10 \mathrm{mM} \mathrm{Mg}^{2+}$, FFA was ineffective (Fig. $7 B$ ). In the same animals, bicuculline $(1 \mathrm{mM}$, as before) produced an even larger rise in population spike size (Fig. $7 C)$. These experiments indicate that $\mathrm{Mg}^{2+}$ blocks GABA release (hence, causing an increase in population spike), but also blocks the ability of FFA to release serotonin and enhance population spikes.

\section{DISCUSSION}

The present study confirms earlier suggestions that activation of the serotonergic system causes an increase in reactivity of the hippocampus to afferent stimulation (Winson, 1980; Klancnik and Phillips, 1991). We now demonstrate that both systemic and local application of FFA cause a marked increase in hippocampal reactivity to PP stimulation with no change in the EPSP slope, indicating that FFA acts locally to release serotonin from terminals within the hippocampus and that no remote site of action is needed to cause the marked potentiation of reactivity to afferent stimulation.

The released serotonin activates several receptors, including 5-HT1a, 5-HT1b, 5-HT2, and 5-HT3 types, all of which are abundant in the hippocampus (Marcinkiewicz et al., 1984; Pazos et al., 1985; Kilpatrick et al., 1987; Wright et al., 1995). Among these, we have strong indications that the 5-HT1a receptor is the one activated by the released serotonin to produce the effect on hippocampal reactivity to afferent stimulation; the 5-HT1a antagonist NAN-190 was the only one to block the effect of FFA applied both locally and peripherally. None of the other antagonists, with the exception of the 5-HT1b agonist (see below), mimicked this action. Furthermore, the 5-HT1a agonist 8-OHDPAT mimicked the effect of FFA, when applied locally, and caused a large increase in DG reactivity to afferent stimulation. This was contrasted with the effect of peripheral application of 8-OH-DPAT, which suppressed population spikes of the DG. The peripheral effect appears to depend on an intact serotonergic system, because it was blocked by PCPA. These results support the assumption that peripheral application of 8-OH-DPAT activates primarily the somadendritic $5 \mathrm{HT}-1 \mathrm{a}$ autoreceptor in the raphe nucleus, which causes hyperpolarization of the serotonergic 


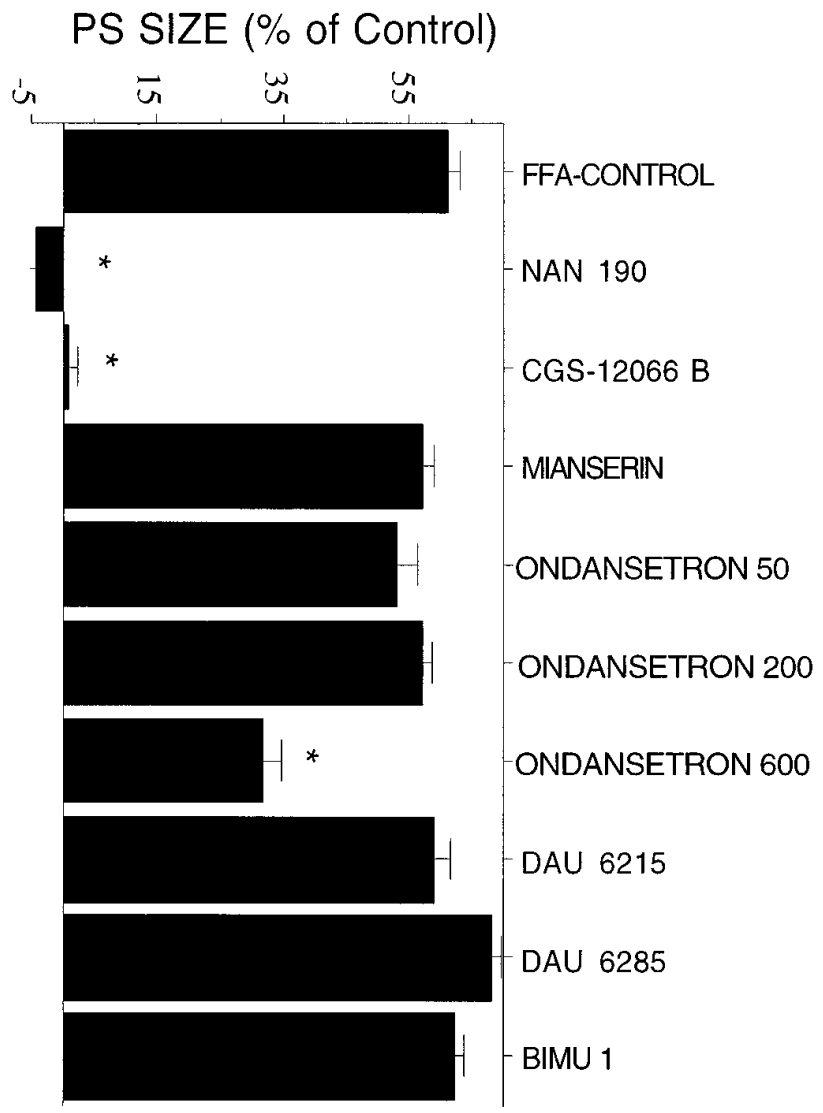

Figure 4. Effects of systemic application of serotonergic drugs on reactivity to FFA. Application of the 5-HT1a receptor antagonist NAN-190, but not of other 5-HT receptor antagonists, blocks the effect of peripheral application of FFA. Same rats as in Table 1.

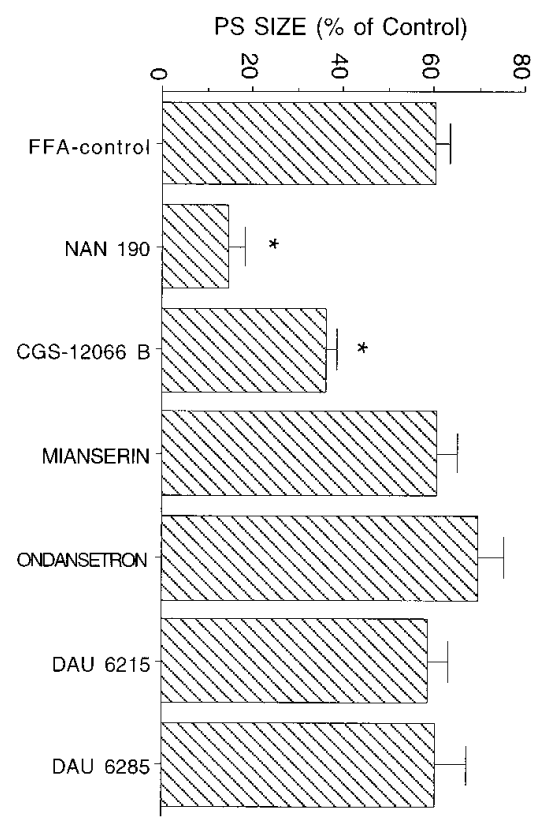

Figure 5. Effects of local application of serotonergic ligands on efficacy of peripheral FFA. Only the 5-HT1a antagonist NAN-190, but not of other serotonin receptor antagonists, blocked the effect of peripheral application of FFA.

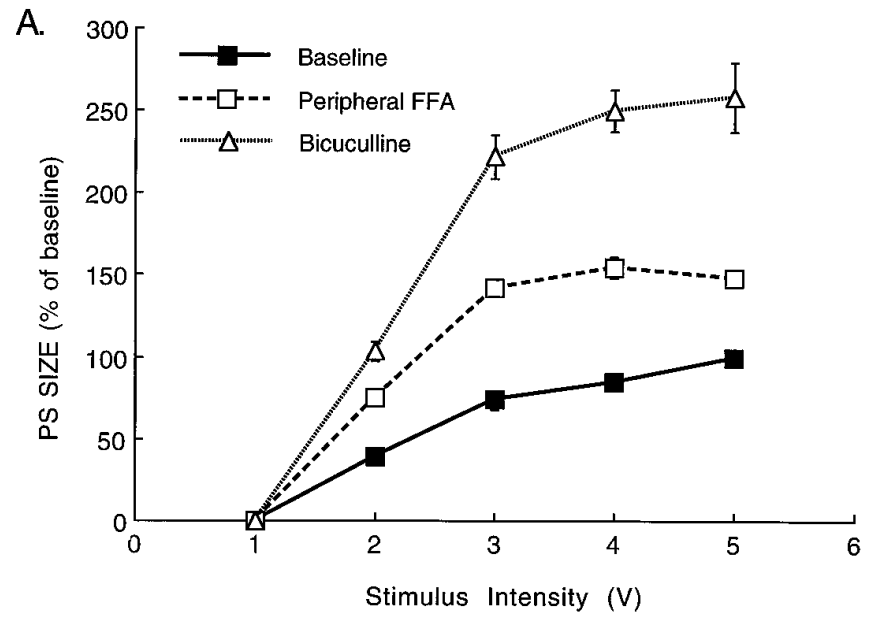

B.

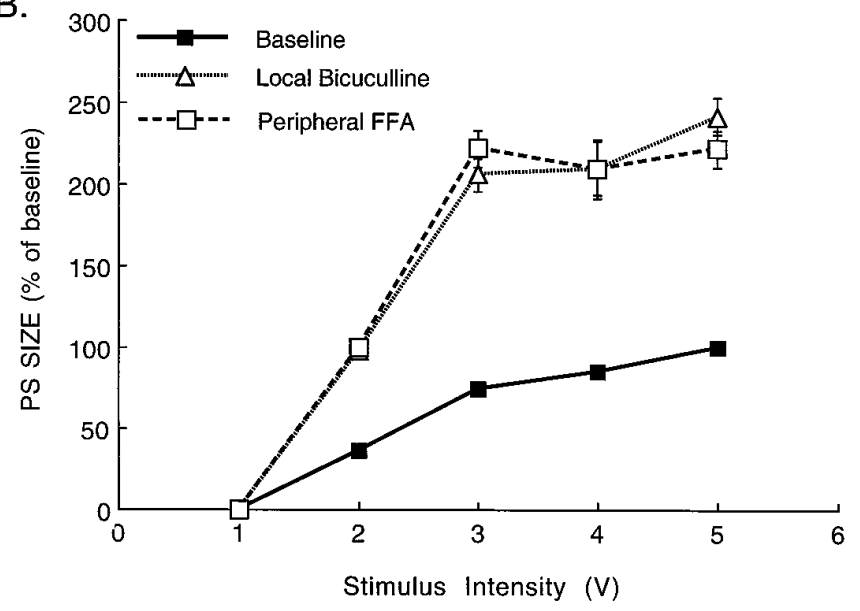

Figure 6. Local application of bicuculline enhances population spike in the hippocampus and blocks the ability of FFA to produce an additional increase in population spike response. $A$, FFA was first applied parenterally, and the typical increase in population spike size was recorded. The recording pipette was then replaced with a pipette containing $1 \mathrm{~mm}$ bicuculline. An additional increase in population spike size was recorded. In $B$, the order was reversed; recording was made first with an $\mathrm{NaCl}$ containing pipette, followed by a bicuculline-containing pipette. FFA was then injected peripherally while recording was made with the bicucullinecontaining pipette. No additional increase in population spike was seen under these conditions.

cells and suppresses their firing. The suppressed raphe activity may release an interneuron from serotonergic, inhibitory control, and this in turn may reduce hippocampal reactivity. Of course, it is possible that 8-OH-DPAT acts elsewhere in or outside the hippocampus to reduce reactivity to afferent stimulation, and this can only be resolved by direct application of the drug into the raphe area.

Systemic application of drugs are difficult to evaluate and compare, because drugs may differ in their ability to cross the bloodbrain barrier and reach the brain, in addition to their different affinities for the different serotonin receptor sites. We have selected the drugs and their concentrations based on the affinities of the drugs to the specific receptors and on the concentrations used by others for similar experiments. Nonetheless, it is reassuring to be able to replicate some of the results of the systemic application with the local application of these drugs.

The blocking action of the 5-HT1b receptor agonist CGS12066-B toward FFA effects is consistent with previous research 


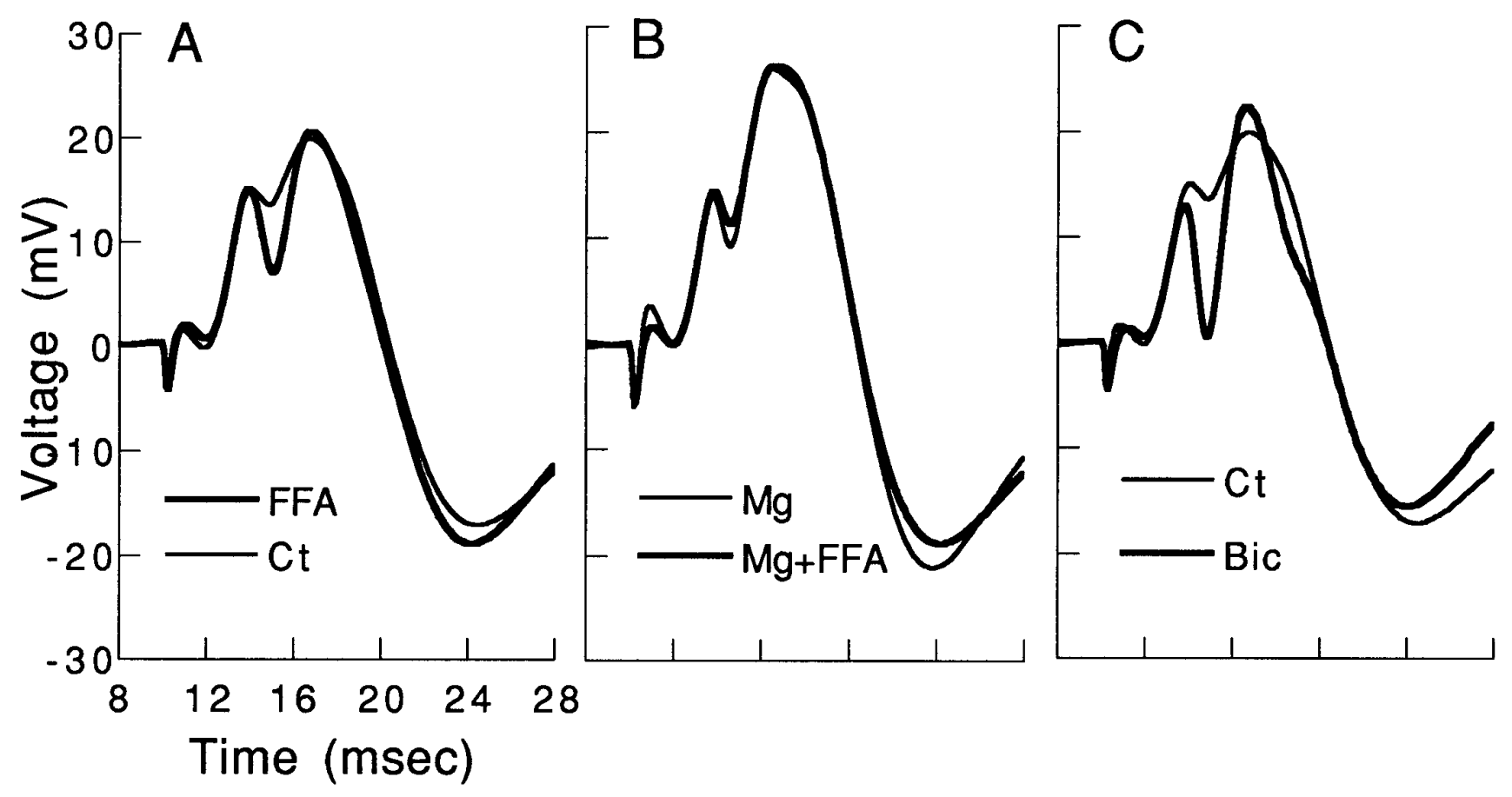

Figure 7. FFA effect on population spike is blocked by a high $\mathrm{Mg}^{2+}$-containing medium. Recording was first made with an FFA-containing pipette $(A)$, followed by a control pipette $(C t)$. The $\mathrm{Mg}^{2+}$-containing pipette $(B)$ produced an increase in population spike, without affecting the slope of the EPSP; however, another pipette containing both $\mathrm{Mg}^{2+}$ and FFA was not as effective in increasing population spike as an FFA-containing pipette by itself. In the same brain location, bicuculline produced a marked increase in population spike $(C)$, as seen above. In all of these recordings, made in approximately the same location, the slope of the EPSP was approximately the same. Calibration on the left is the same for $B$ and $C$.

suggesting that 5-HT1b receptors act as inhibitory presynaptic receptors at the serotonergic nerve terminals (Izumi et al., 1994; Albert et al., 1996). Thus, activating the 5-HT1b receptor will counteract the releasing action of FFA and block its effect on postsynaptic serotonin receptors.

The locus of action of the released serotonin within the DG is probably the inhibitory interneurons innervated by serotonin fibers of raphe origin (Halasy et al., 1992; Ghadimi et al., 1994). These interneurons have been shown to regulate population spike discharge in dentate granular cells in a feedforward manner. These cells express 5-HT3 receptors which, when activated, produce a transient depolarization and discharge of action potentials that hyperpolarizes dentate granular neurons (Ropert and Guy, 1991; Kawa, 1994; Piguet and Galvan, 1994). The 5-HT3 receptor has been shown to control DG activity, and its blockade by ondansetron enhances learning and long-term potentiation (Staubli and Xu, 1995). However, it is not likely that 5-HT3 receptors are the primary receptors to be involved in the present phenomena, because ondansetron, applied peripherally or centrally, did not affect FFA action. Alternatively, it has been shown that the 5-HT1a receptor is more effective in interneurons than in pyramidal or granular cells (Segal, 1990; Schmitz et al., 1995), and so it is likely that activation of this receptor will hyperpolarize interneurons, reduce their inhibitory efficacy, and cause an increase in dentate granular reactivity to PP stimulation. This is a more likely possibility, also, because the 5-HT1a receptor has an order-of-magnitude higher affinity to serotonin than the 5-HT3 receptor. Thus, our results suggest that serotonin, an inhibitory neurotransmitter that hyperpolarizes neurons by activating $\mathrm{K}$ currents, will cause a large potentiation of reactivity of the hippocampus to afferent stimulation simply by its having a preferential inhibitory action on hilar interneurons.

\section{REFERENCES}

Albert PP, Lembo P, Storring JM, Charest A, Saucier C (1996) The 5HT1a receptor: signaling, desensitization and gene transcription. Neuropsychopharmacology 14:19-25.

Azmitia EC, Segal M (1978) An autoradiographic analysis of the differential ascending projections of the dorsal and median raphe nuclei in the rat. J Comp Neurol 179:641-668.

Biegon A, Rainbow TC, McEwen B (1982) Quantitative autoradiography of serotonin receptors in the rat brain. Brain Res 242:197-204.

Freund TF, Gulyas AI, Acsady L, Gorcs T, Toth K (1990) Serotonergic control of the hippocampus via local inhibitory interneurons. Proc Natl Acad Sci USA 87:8501-8505.

Ghadimi BM, Jarolimek W, Misgeld U (1994) Effects of serotonin on hilar neurons and granule cell inhibition in the guinea pig hippocampal slice. Brain Res 633:27-32.

Halasy K, Mietingen R, Szabat E, Freund T (1992) GABAergic interneurons are the major postsynaptic targets of median raphe afferents in the rat dentate gyrus. Eur J Neurosci 4:144-153.

Hall MD, Mestikaway S, Emerit MB, Pichat L, Hamon M, Gozlan H (1985) 8-OH-DPAT binding to pre- and postsynaptic 5-HT sites in various region of the brain. J Neurochem 44:1685-1696.

Hoyer D (1988) Molecular pharmacology and biology of 5-HT1c receptors. Trends Pharmacol Sci 9:89-94.

Izumi J, Washizuka M, Miura N, Hiraga Y, Ikeda Y (1994) Hippocampal serotonin 5-HT 1 receptor enhances acetylcholine release in conscious rats. J Neurochem 62:1804-1808.

Jacobs BL, Azmitia EC (1992) Structure and function of the brain serotonin system. Physiol Rev 72:165-229.

Julius D, Huang KN, Livelli TJ, Axel R, Jessel TM (1990) The 5-HT 2 receptor defines a family of structurally distinct but functionally conserved serotonin receptors. Proc Natl Acad Sci USA 87:928-932.

Kawa K (1994) Distribution and functional properties of 5-HT3 receptors in the rat hippocampal dentate gyrus: a patch clamp study. J Neurophysiol 71:1935-1947.

Kilpatrick GJ, Jones BJ, Tyer MB (1987) Identification and distribution of 5-HT3 receptors in the rat brain using radioligand binding. Nature 330:746-748.

Klancnik JM, Phillips AG (1991) Modulation of synaptic plasticity in the 
Levkovitz Y, Greenberger V, Segal M (1996) The effects of raphe grafts on hippocampal electrophysiology in aged rats. Brain Res 719:234-238.

Marcinkiewicz M, Verge D, Gozlan H, Pichat L, Hamon M (1984) Autoradiographic evidence for the heterogenicity of the 5-HT1 sites in the rat brain. Brain Res 291:159-163.

Pazos A, Palacios JM (1985) Quantitative autoradiographic mapping of serotonin receptors in the rat brain. Brain Res 346:205-230.

Peroutka SJ (1993) 5-Hydroxytryptamine receptors. J Neurochem 60: 408-416.

Piguet P, Galvan M (1994) Transient and long-lasting actions of 5-HT on rat dentate gyrus neurons in vitro. J Physiol (Lond) 481:629-639.

Richter-Levin G, Segal M (1990) Effects of serotonin releasers on the dentate granular cell exitability in the rat. Exp Brain Res 82:199-207.

Ropert N, Guy N (1991) Serotonin facilitates GABAergic transmission in the CA1 region of the rat hippocampus in vitro. J Physiol (Lond) 441:121-136.
Schmitz D, Empson RM, Heinemann U (1995) Serotonin reduces inhibition via 5-HT1a receptors in area CA1 of the rat hippocampal slices in vitro. J Neurosci 15:7217-7225.

Segal M (1980) The action of serotonin in the rat hippocampal slice preparation. J Physiol (Lond) 303:423-439.

Segal M (1990) Serotonin attenuates a slow inhibitory postsynaptic potential in rat hippocampal neurons. Neuroscience 36:631-641.

Staubli U, Xu F (1995) Effects of 5-HT3 receptor antagonism on hippocampal theta rhythm, memory and LTP induction in the freely moving rat. J Neurosci 15:2445-2452.

Winson J (1980) Influence of raphe nuclei on neuronal transmission from perforant pathway through dentate gyrus. J Neurophysiol 44:937-950.

Wright DE, Seroogy KB, Lundgren KH, Davis BM, Jennes L (1995) Comparative localization of serotonin 1a, 1c, and 2 receptor subtype mRNA in rat brain. J Comp Neurol 351:357-373. 